\title{
Amplification of Her-2/neu Gene in Her-2/neu-Overexpressing and -Nonexpressing Breast Carcinomas and Their Synchronous Benign, Premalignant, and Metastatic Lesions Detected by FISH in Archival Material
}

\author{
Ruliang Xu, M.D., Mary Ann Perle, Ph.D., Giorgio Inghirami, M.D., Wai Chan, B.S., Yara Delgado, M.D., \\ Helen Feiner, M.D. \\ New York University School of Medicine, Department of Pathology, New York, New York (RX, MAP, GI, \\ WC, YD); and Quest Diagnostics, Anatomic Pathology, Teterboro, New Jersey (HF)
}

\begin{abstract}
Amplification of Her-2/neu in breast carcinoma is associated with poor prognosis, short disease-free interval, and short survival time in both nodenegative and -positive patients. Little is known about the starting point of amplification of Her-2/ neu and how it progresses from benign to malignant breast lesions. We attempted to address these questions by evaluating amplification of Her-2/neu in benign, premalignant, and malignant lesions using fluorescence in situ hybridization (FISH). Twentysix patients with Her-2/neu-overexpressing invasive ductal carcinomas (as judged by strong immunoreactivity with Her-2/neu antibody) and coexisting lesions of ductal hyperplasia (DH), atypical ductal hyperplasia (ADH), ductal carcinoma in situ (DCIS) in the vicinity of the invasive tumor (as judged by review of the hematoxylin and eosin-stained sections), as well as metastatic carcinoma in axillary lymph nodes (mets) were selected for this study. In the primary carcinomas, a close relationship was present between overexpression as detected by immunohistochemistry (IHC) and amplification as demonstrated by FISH (85\% concordance). Among these patients, amplification of Her-2/neu in ADH was demonstrated in 7 of 13 cases with $A D H$, and in DCIS, in 21 of 22 cases with DCIS. There was no amplification in DH or normal ductal epithelium. Significantly, in all 12 patients with synchronous positive axillary lymph nodes, there was concordant amplification of Her-2/neu in the primary and metastatic carcinoma. Amplification was consistent in
\end{abstract}

Copyright $(2) 2002$ by The United States and Canadian Academy of Pathology, Inc

VOL. 15, NO. 2, P. 116, 2002 Printed in the U.S.A.

Date of acceptance: October 30, 2001.

Address reprint requests to: Helen Feiner, M.D., Quest Diagnostics, Department of Anatomic Pathology, One Malcolm Avenue, Teterboro, NJ 07608 . multifocal metastases, despite morphological heterogeneity in some patients. Amplification ratios increased from ADH to DCIS to invasive carcinoma ( $P$ $<$.01, ADH versus DCIS; $P<.05$, DCIS versus invasive cancer), but there was no difference in amplification ratios between primary cancers and synchronous axillary metastases $(P>.05)$. We also evaluated Her-2/neu amplification in 21 patients without Her-2/neu overexpression in their primary carcinomas (as judged by absent immunoreactivity with Her-2/neu antibody). Three showed amplification in both primary and metastatic lesions, with a low amplification ratio (approximately 2). One patient had amplification in the primary tumor but not in an axillary metastasis. Two patients exhibited slight amplification in the metastatic carcinoma (ratios 1.6 and 2), but not in their primary cancers. This FISH study indicates that amplification of Her2/neu can emerge de novo in any stage of the disease process, from ADH to metastatic lesions, but most often appears first in ADH or DCIS. The degree of Her-2/neu amplification increases with progression to invasive carcinoma, there being no further increase in synchronous metastasis. Our data suggest that amplification of Her-2/neu appears to be mainly involved in initiation of breast oncogenesis and that its role in progression of breast cancers is uncertain.

KEY WORDS: Breast carcinoma, Fluorescent in situ hybridization, Her-2/neu, Immunohistochemistry.

Mod Pathol 2002;15(2):116-124

Her-2/neu, a proto-oncogene located on chromosome $17 \mathrm{q}$, encodes a transmembrane tyrosine kinase with substantial homology to the epidermal growth factor receptor $(1,2)$. Amplification or overexpression of Her-2/neu has been shown to be an 
independent prognostic factor associated with resistance to some forms of adjuvant therapy and sensitivity to others, short disease-free interval, and short survival time in both node-negative and -positive patients (3-6). It also is an objective indicator of high histological grade, nuclear atypia, biological aggressiveness of breast cancers, and high metastatic potential (7-9). Approximately $10-34 \%$ of invasive breast cancers have overexpressed or amplified Her-2/neu $(2,10)$. However, there is uncertainty regarding how Her-2/ neu overexpression or amplification develops with evolution of cancer and its progression. Some studies demonstrate that it may start as early as in a benign proliferative lesion such as ductal hyperplasia (DH) or atypical ductal hyperplasia (ADH) (11-13), but others argue that amplification emerges only at or after the stage of ductal carcinoma in situ (DCIS) (14-16).

Knowing at which stage amplification or overexpression of Her-2/ neu occurs is important in understanding the development of breast cancer. Animal and in vitro studies suggest that overexpression of Her-2/neu is a cause rather than a consequence of cancers $(17,18)$. Transgenic mice engineered to overexpress the HER-2/ neu-erbB-2 proto-oncogene under the control of a mammary-specific promoter develop mammary tumors, and these serve as a model for human breast cancer (19). However, in humans, some studies have shown opposite results. For example, one study demonstrated that overexpression of p53, not Her-2/ neu, increases the risk of progression from benign lesions to tumor in women (20). A report also suggests that overexpression of Her-2/ neu in benign lesions does not increase the risk of development of invasive carcinoma (15). Thus, the notion that overexpression of Her-2/neu demonstrated by immunohistochemistry (IHC) might be involved in initiation rather than progression of breast oncogenesis is inconclusive and challengeable. Part of the problem is that those studies compared Her-2/neu overexpression detected by IHC among the different lesions in different patients. In addition, almost all the data are obtained by IHC, which has such intrinsic problems as variable sensitivity, loss of antigenicity caused by fixation and storage, difficulty with standardization, and false positivity $(3,21)$. Thus, the exact role of this oncoprotein in the etiology and pathogenesis of breast carcinoma remains obscure.

We approached this problem by comparison of amplification of Her-2/neu among the spectrum of diseases (benign, premalignant, malignant, and metastatic carcinomas) in a series of patients with either Her-2/neu-overexpressing or -nonexpressing invasive ductal carcinoma, using fluorescence in situ hybridization (FISH) in paraffin sections from archival material. The patients were selected on the basis of Her-2/ neu immunostaining of their invasive primary carcinomas, the presence of pro- liferative lesions in the vicinity of the invasive cancer, and the presence of metastases. This allowed us to evaluate amplification of Her-2/ neu in DH, ADH, DCIS, primary, and metastatic carcinoma in a synchronized fashion by a reproducible and sensitive standardized technique, FISH $(3,22)$.

\section{MATERIALS AND METHODS}

\section{Patients}

Ninety-seven patients who were diagnosed with invasive breast carcinoma at the New York University Medical Center, Tisch Hospital between 1996 and 1999 who had Her-2/neu overexpression in their primary cancers, determined prospectively by IHC (procedure described below), were reviewed. IHC scores of $2+$ or $3+$ on a scale of 0 to $3+$ defined overexpression $(23,24)$. Twenty-six of these 97 patients with Her-2/neu-overexpressing invasive carcinomas were selected for study based on a review of hematoxylin and eosin-stained (H\&E) sections to identify synchronous benign, premalignant, and metastatic lesions suitable for FISH evaluation. Among them, 25 patients had coexisting DCIS, 13 of whom had the full spectrum of $\mathrm{DH}, \mathrm{ADH}$, and DCIS in the region of the invasive carcinomas. In addition, 12 patients with invasive carcinoma also had one or multiple synchronous positive axillary lymph nodes.

The patients' ages ranged from 30 to 81 years with a median of 53 years. The tumor size ranged from 0.4 to $9.5 \mathrm{~cm}$ (median, $1.5 \mathrm{~cm}$ ). The majority of tumors (23/26) were pure invasive ductal carcinomas; three had additional lobular, mucinous, or apocrine components. Among the 26 carcinomas, 19 were poorly differentiated, 6 and 2 being moderately and well differentiated, respectively (Table 1).

Twenty-one patients with Her-2/neu-nonexpressing invasive carcinomas (negative by IHC) were selected for the presence of concurrent metastatic carcinoma in axillary lymph nodes. The patients' ages as well as tumor size were similar to the Her-2/neu-overexpressing group, although there were more low- and intermediate-grade tumors in this group (Table 2). The patients' ages ranged from 30 to 80 years (median, $60 \mathrm{y}$ ), and the tumor size varied from 0.8 to $4.5 \mathrm{~cm}$ (median, $2.3 \mathrm{~cm}$ ). The numbers of poorly, moderately, and well-differentiated carcinomas were 11,5 , and 4 , respectively. The majority of tumors were invasive ductal carcinomas. However, four had additional lobular, apocrine, tubular, and metaplastic components, and one was a pure medullary carcinoma (Table 2). All tissues had been fixed in $10 \%$ formalin for 4 to 12 hours at room temperature, routinely processed, and embedded in paraffin blocks. 
TABLE 1. Clinical and Pathological Data in 26 Patients with Her-2/neu-Overexpressing Primary Breast Cancers

\begin{tabular}{|c|c|c|c|c|c|}
\hline No. & Patient Age (y) & Type of Carcinoma & Size $(\mathrm{cm})$ & $\begin{array}{l}\text { Histological Grade } \\
\text { (Differentiation) }\end{array}$ & DCIS Type \\
\hline 1 & 79 & ID-AP & 1.4 & Poor & $\mathrm{CM}$ \\
\hline 2 & 74 & ID & 1.2 & Moderate & CR with necrosis \\
\hline 3 & 53 & ID & 1.8 & Poor & $\mathrm{CM}$ \\
\hline 4 & 51 & ID-LB & 1.8 & Poor & $\mathrm{CM}$ \\
\hline 5 & 59 & ID & 1.5 & Poor & $\mathrm{CM}$ \\
\hline 6 & 46 & ID & 0.4 & Moderate & CM, S, CR, MC \\
\hline 7 & 48 & ID & 1.5 & Well & $\mathrm{S}, \mathrm{CR}, \mathrm{MC}$ \\
\hline 8 & 72 & ID & 0.5 & Poor & S, CR, CL \\
\hline 9 & 65 & ID & 2.5 & Moderate & $\mathrm{CM}, \mathrm{S}$ \\
\hline 10 & 65 & ID & 1.8 & Poor & $\mathrm{CR}$ \\
\hline 11 & 73 & ID & 1.5 & Moderate & $\mathrm{CM}$ \\
\hline 12 & 49 & ID & 0.8 & Poor & CM, S, CR \\
\hline 13 & 56 & ID & 1.5 & Poor & $\mathrm{S}$ \\
\hline 14 & 62 & ID & 1.4 & Poor & CM, S \\
\hline 15 & 53 & ID & 1.5 & Well & $\mathrm{CR}$ \\
\hline 16 & 38 & ID & 5.0 & Poor & $\mathrm{CM}$ \\
\hline 17 & 46 & ID & 1.6 & Moderate & CM, CR, MC, S \\
\hline 18 & 58 & ID & 1.4 & Poor & $\mathrm{S}$ \\
\hline 19 & 68 & ID & 1.4 & Poor & CR \\
\hline 20 & 43 & ID & - & Poor & CM, S \\
\hline 21 & 35 & ID & 9.5 & Poor & CM, S, CR \\
\hline 22 & 47 & ID & 2.2 & Poor & CM, MC, CL \\
\hline 23 & 30 & ID & 1.3 & Poor & $\mathrm{CM}$ \\
\hline 24 & 33 & ID-MU & 1.0 & Moderate & CM, S \\
\hline 25 & 81 & ID & 1.2 & Poor & CM, S \\
\hline 26 & 63 & ID & 6.0 & Poor & None \\
\hline
\end{tabular}

ID, invasive ductal carcinoma; ID-LB, invasive ductal carcinoma with lobular features; ID-AP, invasive ductal carcinoma with apocrine features; ID-MU, invasive ductal carcinoma with mucinous features; DCIS, ductal carcinoma in situ; CM, comedo type; S, solid type; CR, cribriform type; MC, micropapillary type; CL, clinging type.

TABLE 2. Clinical and Pathological Data and Amplification of Her-2/neu Gene in Her-2/neu-Nonexpressing Primary Invasive and Metastatic Carcinomas Detected by Fluorescence In Situ Hybridization

\begin{tabular}{|c|c|c|c|c|c|c|}
\hline \multirow[t]{2}{*}{ No. } & \multirow[t]{2}{*}{ Age (y) } & \multirow[t]{2}{*}{ Type } & \multirow[t]{2}{*}{ Size $(\mathrm{cm})$} & \multirow{2}{*}{$\begin{array}{l}\text { Histological Grade } \\
\text { (Differentiation) }\end{array}$} & \multicolumn{2}{|c|}{$\begin{array}{c}\text { Ratio of Her-2 to Copy } \\
\text { Numbers of Chromosome } 17\end{array}$} \\
\hline & & & & & IC & Mets \\
\hline 1 & 69 & ID & 1.8 & Moderate & 1.0 & 0.9 \\
\hline 2 & 60 & ID & 1.1 & Moderate & 1.0 & 0.9 \\
\hline 3 & 46 & ID & 3.0 & Well & 1.0 & 1.0 \\
\hline 4 & 37 & ID & 3.0 & Poor & 1.0 & 1.1 \\
\hline 5 & 38 & ID & 1.9 & Well & 1.0 & 1.1 \\
\hline 6 & 53 & ID & 2.1 & Poor & 1.0 & $1.0 / 1.2$ \\
\hline 7 & 61 & ID & 1.2 & Well & 1.0 & 1.2 \\
\hline 8 & 37 & ID & 3.5 & Poor & 1.0 & 1.2 \\
\hline 9 & 76 & ID & 1.2 & Poor & 1.0 & 1.3 \\
\hline 10 & 76 & ID & 4.0 & Poor & 1.0 & 1.3 \\
\hline 11 & 53 & ID & 1.5 & Poor & 1.1 & 1.0 \\
\hline 12 & 80 & ID-LB & 4.5 & Moderate & 1.1 & $1.2 / 2.0^{a}$ \\
\hline 13 & 30 & Med & 0.8 & - & 1.1 & 1.6 \\
\hline 14 & 55 & ID & 1.1 & Poor & 1.2 & 1.0 \\
\hline 15 & 70 & ID & 3.1 & Moderate & 1.2 & 1.0 \\
\hline 16 & 78 & ID-Apo + Met & 2.5 & Poor & 1.4 & 1.0 \\
\hline 17 & 50 & ID & 2.3 & Poor & 1.4 & 1.4 \\
\hline 18 & 56 & ID & 1.1 & Well & 1.9 & 1.9 \\
\hline 19 & 68 & ID-LB & 2.6 & Moderate & 2.1 & 1.0 \\
\hline 20 & 80 & ID & 3.0 & Poor & 2.1 & 1.9 \\
\hline 21 & 73 & ID & 2.5 & Poor & 2.1 & 2.0 \\
\hline
\end{tabular}

ID, invasive ductal carcinoma; ID-LB, invasive ductal carcinoma with lobular features; ID-Apo + Met, invasive ductal carcinoma with apocrine and metaplastic features; Med, medullary carcinoma; IC, invasive carcinoma; Mets, metastatic carcinoma.

${ }^{a}$ Results of mets in two separate lymph nodes.

\section{Immunohistochemistry}

Immunohistochemical evaluation of cell membrane staining for Her-2/neu was performed on $4-\mu \mathrm{m}$ sections of formalin-fixed, paraffin-embedded tissues $(20,25)$. The antigenicity of all paraffin-embedded tissues was enhanced by heat-induced antigen retrieval according to manufacturer protocols. A cocktail of two mouse monoclonal antibodies, c-neu
(AB-3) clone 3B3 from Oncogene, Inc. (Cambridge, MA) and NCL-CB11 from Novocastra Laboratories (New Castle upon Tyne, UK), was used to maximize the detection power. Final concentrations of c-neu (AB-3) clone 3B3 and NCL-CB11 were 1:200, and 1:40, respectively. Antibody-antigen reactivity was visualized by using 3,3'-diaminobenzidine. All procedures were carried out prospectively in a Ventana NexES 
(Ventana Medical Systems, Tucson, AZ) automated immunostainer. Scoring was based on the membrane reactivity for antibodies and was similar to that of the DAKO HercepTest, with minor modification. Weak membrane staining was defined as $1+$; intermediate or strong membrane staining in $>70 \%$ of the tumor cell population, as $2+$; and very strong membrane staining in $>70 \%$ of the tumor cell population, as $3+$. Cytoplasmic staining and weak or no membrane staining was considered to be negative.

\section{Fluorescent In Situ Hybridization}

FISH was performed based on dual-color interphase analysis by using combined Her-2/neu (rhodamine labeled) and chromosome 17- $\alpha$ satellite DNA probes (CEP17, fluorescein labeled) from Vysis (Downers Grove, IL), Inc (26). The alpha satellite DNA probe for chromosome 17 was included as an internal control for chromosomal aneuploidy because the Her-2/neu gene is located on chromosome $17(5,22)$. Briefly, two $4-\mu \mathrm{m}$-thick paraffin sections for each case were prepared. One section was stained with $H \& E$ and examined for the lesions of interest. The lesions corresponding to the H\&E slide were marked with a diamond-tipped scribe on the duplicate unstained section. The slides were deparaffinized and digested by incubation with proteinase $\mathrm{K}(25 \mathrm{mg} / \mathrm{mL})$ at $37^{\circ} \mathrm{C}$ for 10 minutes. Then they were processed as follows: pretreatment, re-fixation with formalin, washing, dehydration, and denaturation at $72^{\circ} \mathrm{C}$ for 5 minutes. Hybridization with fluorescent-labeled probes was achieved by incubation overnight $(16 \mathrm{~h})$ in a humidified $37^{\circ} \mathrm{C}$ incubator. After hybridization, slides were washed in $0.1 \times$ SCC at $72^{\circ} \mathrm{C}$ for 2 minutes followed by counterstaining with 4, 6 diamidin-2-phenylindoldihydrochloride-antifade. Fluorescence was observed in an Olympus BX60 fluorescence microscope at $1000 \times$ magnification with a computerized imaging system (27). At least 50 cells in each histologic lesion and control cells were randomly evaluated for nuclear Her-2/neu amplification. Results were expressed as amplification ratio, the ratio of the number of Her-2/ neu to those of CEP17 signals in the same cell. A score of $>1.5$ was considered to indicate amplification (22). Normal ductal epithelia and lymphocytes in the same specimen served as the negative controls. Photographic images were captured with a computer-controlled CCD camera and processed with Vysis, Inc.

\section{Statistical analysis}

ANOVA and Student's $t$ tests were applied when appropriate.

\section{RESULTS}

Concordance between Immunohistochemical Overexpression and FISH Amplification of Her-2/ neu in Primary Invasive Ductal Carcinomas

The ages and pathological features of 26 patients with Her-2/neu-overexpressing breast cancers are shown in Table 1 . These 26 invasive ductal carcinomas had IHC scores of ++ or +++ (Tables 3 and 4). Amplification of Her-2/neu was observed in the vast majority of cases $(22 / 26)$, with amplification ratios ranging from 1.8 to 10.6 (Tables 3 and 4). Amplification was not seen in two poorly differentiated and one well-differentiated carcinoma (3/ 26), which showed overexpression as judged immunohistochemically (Table 3). It appears that the IHC scores correlated quantitatively with amplification ratios (Tables 3 and 4 ).

Amplification of Her-2/neu in DH, ADH, DCIS, and Invasive Carcinomas in Patients with Her-2/ neu-Overexpressing Primary Invasive Cancers

Breast tissue from 25 patients with Her-2/neuoverexpressing breast cancers was examined for amplification of Her-2/neu in co-existing benign (DH and $\mathrm{ADH}$ ) lesions, premalignant (DCIS) lesions, and invasive primary carcinomas in the same specimen. The results are summarized in Table 3 and illustrated in Figure 1.

There was close concordance of amplification of Her-2/neu between invasive carcinomas and coexisting carcinomas in situ. A rare case (Case 19; Table 3) showed discordance, in which amplification was seen in the high-grade invasive but not in the low-grade (cribriform) in situ component. Among three overexpressing but nonamplified invasive carcinomas, none had Her-2/neu amplification in the DCIS (Cases 14-16; Table 3).

In 13 patients with the full spectrum of benign to malignant lesions examined, there was complete concordance between the invasive and in situ components as mentioned above. Interestingly, 7 of these $13(54 \%)$ cases also showed low or moderate amplification of Her-2/neu in $\mathrm{ADH}$. The pattern of distribution of those positive cells in the ducts with $\mathrm{ADH}$ is noteworthy. In some cases, positive cells did not completely occupy the entire duct lining but were located at the base with nonamplified cells on the luminal aspect; alternatively, they comprised only a certain percentage of irregularly distributed duct cells. No amplification was noted in any of the coexisting DH lesions.

Another interesting finding was that the amplification ratios were related to the stage of the lesion, with the highest ratio in the invasive component. For 21 cases in which there was concordance between invasive cancers and DCIS, the average am- 
TABLE 3. Amplification of Her-2/neu in 26 Overexpressing Invasive Breast Carcinomas and Coexisting DCIS, ADH, and DH Detected by FISH on Archival Material

\begin{tabular}{|c|c|c|c|c|c|}
\hline \multirow[t]{2}{*}{ No. ${ }^{a}$} & \multirow[t]{2}{*}{ Immunochemistry } & \multirow[t]{2}{*}{ IC } & \multicolumn{3}{|c|}{$\begin{array}{l}\text { Ratio of Her-2/neu to Copy Number of } \\
\text { Chromosome } 17\end{array}$} \\
\hline & & & DCIS & $\mathrm{ADH}$ & $\mathrm{DH}$ \\
\hline 1 & +++ & 1.1 & 1.3 & 1.2 & 0.9 \\
\hline 2 & ++ & 2.0 & 1.8 & 1.5 & 1.1 \\
\hline 3 & +++ & 3.2 & 2.7 & 1.0 & 1.0 \\
\hline 4 & $++1+++$ & 3.6 & 4.1 & 2.7 & 1.2 \\
\hline 5 & +++ & 4.9 & 4.4 & 0.9 & 1.0 \\
\hline 6 & +++ & 5.0 & 5.0 & 2.5 & 1.0 \\
\hline 7 & +++ & 6.0 & 3.2 & 1.0 & 1.0 \\
\hline 8 & +++ & 6.1 & 5.1 & 4.8 & 1.0 \\
\hline 9 & +++ & 6.2 & 6.1 & 2.2 & 0.9 \\
\hline 10 & +++ & 7.3 & 7.7 & 1.3 & 1.0 \\
\hline 11 & +++ & 7.7 & 6.7 & 5.6 & 1.1 \\
\hline 12 & +++ & 7.8 & 5.8 & 4.7 & 1.0 \\
\hline 13 & +++ & 9.9 & 7.3 & 6.5 & 1.0 \\
\hline 14 & +++ & 1.1 & 1.2 & & \\
\hline 15 & ++ & 1.1 & 1.3 & & \\
\hline 16 & ++ & 1.3 & 1.1 & & \\
\hline 17 & ++ & 2.1 & 1.8 & & \\
\hline 18 & +++ & 2.2 & 2.5 & & \\
\hline 19 & ++ & 5.1 & 1.0 & & \\
\hline 20 & +++ & 5.8 & 4.9 & & \\
\hline 21 & +++ & 6.0 & 4.7 & & \\
\hline 22 & +++ & 7.7 & 6.7 & & \\
\hline 23 & +++ & 9.7 & 8.6 & & \\
\hline 24 & +++ & 10.5 & 7.7 & & \\
\hline 25 & +++ & 10.6 & 6.5 & & \\
\hline 26 & +++ & 8.4 & NP & & \\
\hline
\end{tabular}

DCIS, ductal carcinoma in situ; ADH, atypical ductal hyperplasia; DH, ductal hyperplasia; FISH, fluorescence in situ hybridization; IC, invasive carcinoma; NP, not present.

${ }^{a}$ Order is the same as in Table 1.

plification ratio for the invasive component was 6.2, and for the DCIS, it was 5.2. For those 13 cases, having the whole spectrum of benign and malignant lesions, the average amplification ratios for $\mathrm{DH}, \mathrm{ADH}, \mathrm{DCIS}$, and invasive cancers were 1.0, 4.1, 5.7, and 6.6, respectively (Table 3). With $\chi^{2}$ testing, the differences among $\mathrm{DH}, \mathrm{ADH}, \mathrm{DCIS}$, and invasive carcinoma are statistically significant $(P<.01$,

TABLE 4. Amplification of Her-2/neu in Her-2/neu-Overexpressing Primary and Metastatic Breast Carcinomas

\begin{tabular}{rccc}
\hline & & \multicolumn{2}{c}{$\begin{array}{c}\text { Ratio of Her-2/neu to } \\
\text { Copy Number of } \\
\text { No. }\end{array}$} \\
& Immunohistochemistry & \multicolumn{2}{c}{ Chromosome 17} \\
\cline { 3 - 4 } & & IC & Mets \\
\hline 16 & ++ & 1.3 & $1.1 / 1.2$ \\
18 & +++ & 2.2 & 1.9 \\
17 & ++ & 2.1 & 2.0 \\
20 & +++ & 5.8 & $4.6 / 4.5$ \\
21 & +++ & 6.0 & $5.0 / 6.4$ \\
9 & +++ & 6.2 & 5.8 \\
22 & +++ & 7.7 & $5.0 / 5.4$ \\
11 & ++ & 7.7 & $7.7 / 8.7^{b}$ \\
26 & +++ & 8.4 & $8.4 / 10.3$ \\
23 & +++ & 9.7 & $10.8 / 13.6$ \\
24 & +++ & 10.5 & 8.7 \\
25 & +++ & 10.6 & 4.5 \\
\hline
\end{tabular}

IC, invasive carcinoma; Mets, metastatic carcinoma.

${ }^{a}$ Order is the same as in Table 1.

${ }^{b}$ Two numbers represent the amplification ratios in two morphologically different tumor foci in one or more positive axillary lymph nodes.
$\mathrm{DH}$ versus $\mathrm{ADH} ; P<.01, \mathrm{ADH}$ versus $\mathrm{DCIS} ; P<.05$, DCIS versus invasive carcinomas). Apparently, there was an upward tendency of amplification with progression of disease.

Ploidy status of the carcinomas is also demonstrated by visualization of Her-2/neu signals directly on the slides. Among 25 overexpressors of Her-2/neu, 5 cases were identified to be aneuploid, with multiple copies of chromosome 17 (numbers ranging from 3 to 6) in both DCIS and invasive carcinomas. However, the ratios of Her-2/neu signals to an alpha satellite in chromosome 17 were 2 to 7.8 , indicating that the increase of Her-2/neu copies is caused by amplification of Her-2/neu in addition to the increased copy number of chromosome 17.

\section{Amplification of Her-2/neu in Primary and Synchronous Metastatic Carcinoma in Axillary Lymph Nodes of Patients with Her-2/neu-Overexpressing Primary Invasive Carcinomas}

Twelve Her-2/neu-overexpressing carcinomas were selected for comparison of amplification between the primary and synchronous metastases in axillary lymph nodes. Five of 12 patients had multiple positive axillary lymph nodes or multiple foci with different morphology in a single node (multiple lymph node equivalents). In all of these patients, 

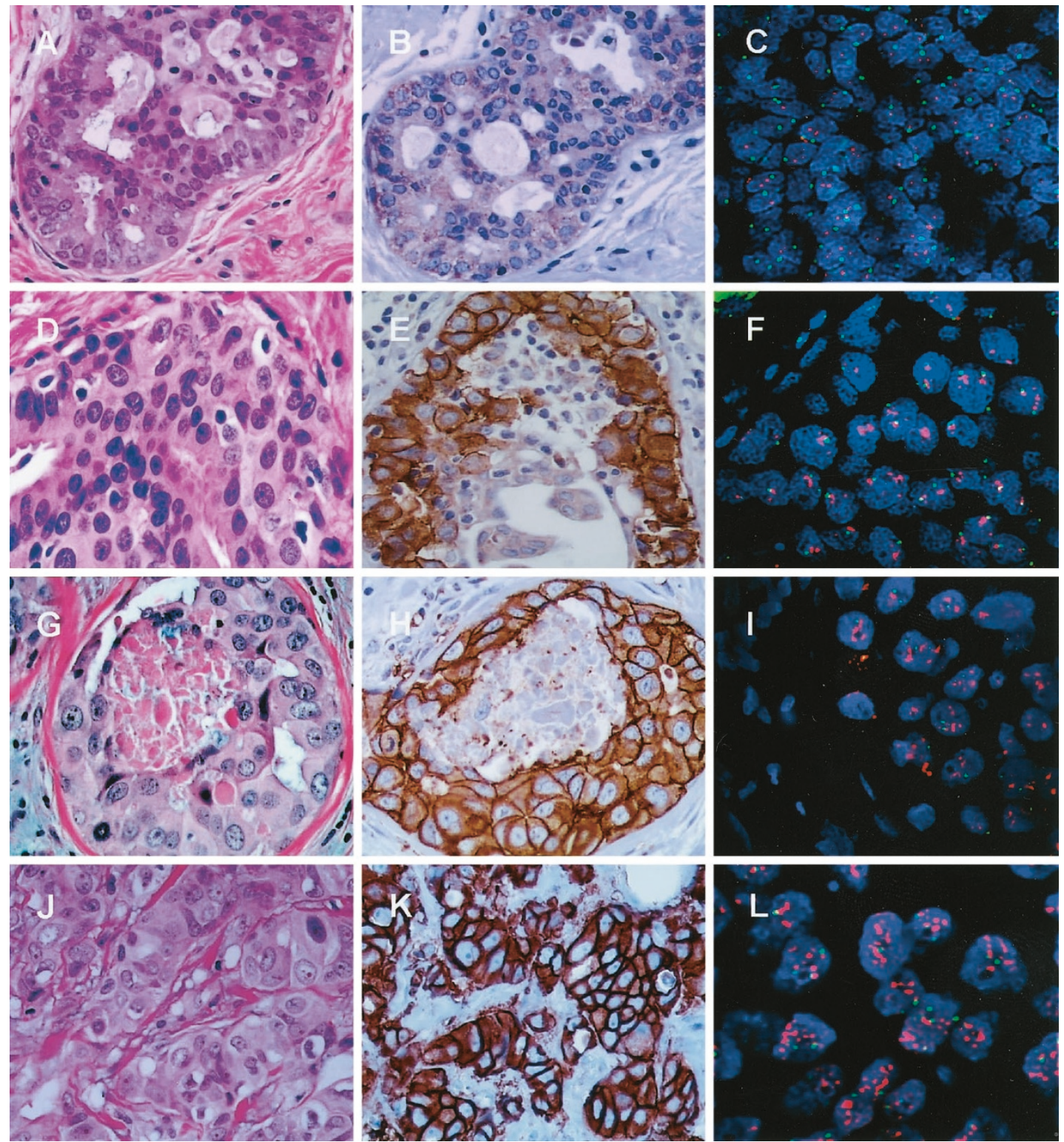

FIGURE 1. Amplification of Her-2/neu in Her-2/neu-overexpressing invasive breast carcinoma and synchronous ductal hyperplasia (DH), atypical ductal hyperplasia (ADH), and ductal carcinoma in situ (DCIS) detected by fluorescence in situ hybridization (FISH). A-C, ductal hyperplasia; D-F, atypical ductal hyperplasia; G-I, DCIS; J-L, invasive ductal carcinoma. A, D, G, and J, hematoxylin and eosin sections; B, E, H, and K; immunohistochemical studies; C, F, I, and L, FISH results. Red and green signals represent Her-2/neu and chromosome 17 hybridizations, respectively, and blue DAPI stain demonstrates the nuclei.

there was concordance of amplification between the primary and metastatic carcinomas.

Amplification was seen in both primary and metastatic carcinomas in 11 of 12 cases, including in 6 cases with multiple positive lymph nodes or equivalents (Table 4, Fig. 2). The one immunohistochemically positive case without amplification in the primary tumor (Case 16; Table 4) also did not show amplification in metastatic carcinoma in two lymph nodes examined. There was no difference of amplification between metastatic and primary carcinomas $(P>.05)$. The data suggest that amplification of Her-2/ neu is quite stable once the alteration of the gene has been established in the primary carcinoma, at least in synchronous metastases.
Amplification of Her-2/neu in Primary and Synchronous Axillary Lymph Node Metastases of Patients with Her-2/neu-Nonexpressing (Immunohistochemically Negative) Primary Invasive Carcinomas

Among 21 patients with Her-2/neu-nonexpressing primary carcinomas, three (Cases 18, 20, and 21; Table 2) showed amplification of Her-2/ neu in both primary and metastatic lesions, with a low amplification ratio (approximately 2 ).

One patient (Case 19; Table 2) had amplification in the primary tumor, but not in a positive lymph node. Amplification of Her-2/neu was observed in only one of two positive axillary lymph nodes in one 

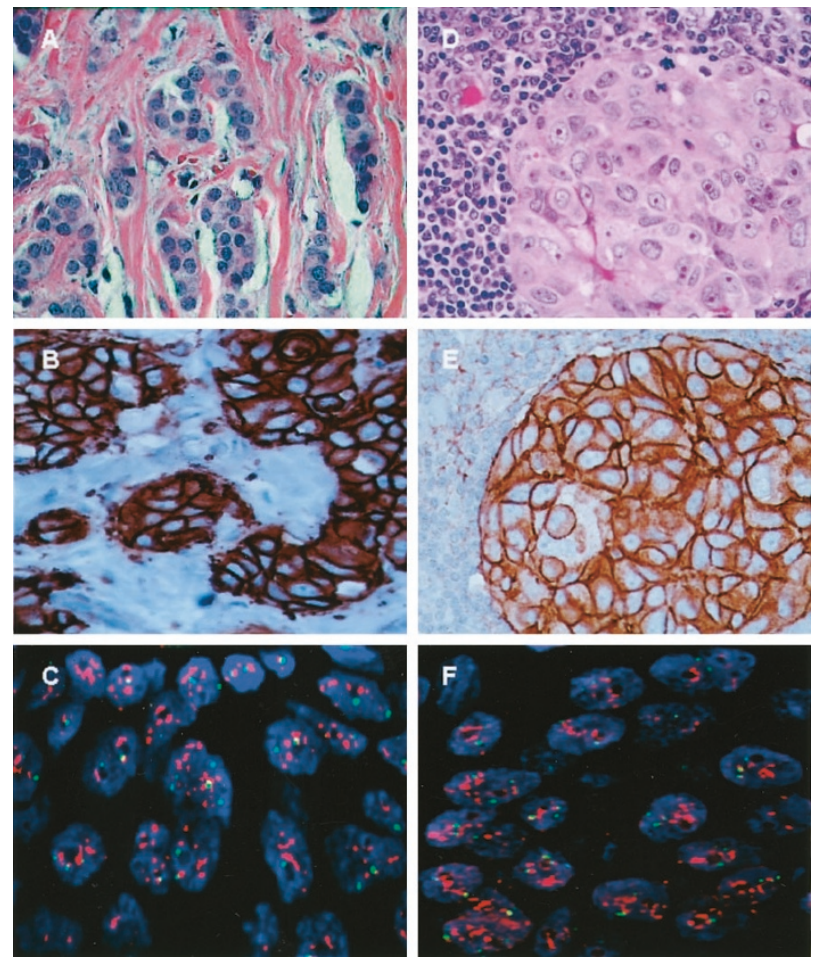

FIGURE 2. Amplification of Her-2/neu in primary and synchronous metastatic carcinoma with Her-2/neu-overexpressing primary invasive carcinoma. A-C, primary carcinoma; D-F, nodal metastatic carcinoma. $\mathbf{A}$ and $\mathbf{D}$, hematoxylin and eosin sections; $\mathbf{B}$ and $\mathbf{E}$, immunohistochemical studies; $\mathbf{C}$ and $\mathbf{F}$, fluorescence in situ hybridization results. Red, green, and blue signals are described in Figure 1.

case (Case 12; Table 2). An additional case (Case 13; Table 2) showed a low degree of amplification of Her-2/neu in the metastasis (ratios, 1.6) but not in the concurrent primary medullary carcinoma.

\section{DISCUSSION}

In our study, amplification and overexpression of Her-2/neu were closely related in 22 of 26 cases of Her-2/neu-overexpressing and in 17 of 21-nonexpressing invasive breast carcinomas (85\% and $81 \%$ concordance, respectively), as detected by IHC and FISH. This concordance is consistent with other reports (overall concordance rate, approximately 85$97 \%$; 38, 39). The possible causes of discrepancy between the results of FISH and IHC include the lower sensitivity and false positivity of IHC caused by antigen alteration, sampling, and erroneous interpretation. Enhanced expression of Her-2/neu by gene mutation or up-regulation without increased gene copy number is another plausible explanation in a subset of breast cancers $(39,40)$. Most of the discrepancy exists among cases with weak expression of protein detected by IHC and low gene amplification revealed by FISH (39). Low expression (1+ positive IHC score) has uncertain prognostic significance and uncertain impact on other clinical parameters (41) and was not addressed in this study. The prognostic effect of overexpression without amplification is also unclear because there is no study to address this issue. Amplification of the gene alone, on the other hand, has more definite negative prognostic impact than does overexpression alone (40). Furthermore, the tumors showing both Her-2/neu amplification and overexpression exhibit more aggressive biological characteristics than those with only overexpression or immunonegativity (8). Because there is a small subset of cases with only gene amplification or only protein overexpression, use of either IHC or FISH alone for detection may miss these patients. Thus, the combination of IHC and FISH optimizes selection of patients for anti-Her$2 /$ neu therapy (i.e., Herceptin treatment), and others have shown that it improves prediction of prognosis (42-44).

This study has demonstrated that amplification of Her-2/neu starts at the stage of ADH or DCIS. It rarely appears de novo in primary invasive or in metastatic carcinoma. Furthermore, there was an increase of amplification from benign lesion to premalignant lesion to invasive carcinoma in this group of patients. These data support the idea that amplification of Her$2 /$ neu may initiate breast oncogenesis and may be an indicator of transformation from high grade DCIS to invasive cancer, as suggested by others (14). Amplification of Her-2/neu in breast lesions was previously considered to play a role only in the early stage of tumorigenesis of breast cancers. A recent case control study conducted at the Mayo Clinic has shown that women with benign breast biopsies demonstrating both HER-2/neu amplification and a proliferative histopathologic diagnosis ( $\mathrm{DH}$ or $\mathrm{ADH}$ ) may be at substantially increased risk for subsequent breast cancer (12). Study of amplification or overexpression of Her$2 /$ neu in other cancers, for example, pancreatic carcinoma, has demonstrated that amplification or overexpression is involved in the development and progression of pancreatic cancer (28). Thus, the results of those studies, together with our findings, suggest that amplification of Her-2/neu is likely implicated in both initiation and progression of breast cancers. Amplification of Her-2/neu was found in the metastases, not in primary lesions in two patients. It appears that de novo amplification can rarely occur at the stage of metastasis, or alternatively, an undetected subset of Her-2/neu amplified primary tumor cells selectively metastasized. It is of interest that loss of Her-2/neu amplification was found in the metastatic carcinoma in one patient. Perhaps a subset of tumor cells that have higher metastatic potential associated with a factor other than Her-2/neu amplification or overexpression selectively metastasized in this patient.

Amplification of Her-2/neu in 7 of $12 \mathrm{ADH}$ cases is quite striking. Acknowledging that boundaries in the definition of $\mathrm{ADH}$ vary among pathologists, our 
data indicate that Her-2/neu amplification can be established at a stage as early as $\mathrm{ADH}(12,13)$. An interesting observation in our study was that amplification of Her-2/neu in some cases was not evenly distributed; rather, it was geographically or focally distributed in $\mathrm{ADH}$. These findings suggest that amplification of Her-2/neu in these ducts is a de novo process. Pagetoid spread of DCIS in hyperplastic ducts, however, can produce a similar distribution pattern, because Her-2/neu protein has been shown to be involved in control of motility of tumor cells in an in vitro study $(18,33)$. A study of $\mathrm{ADH}$ in patients in whom this was the most advanced lesion type would exclude such a possibility. Furthermore, it should be acknowledged that cases of $\mathrm{ADH}$ as the most advanced proliferative lesion (an entity that is well characterized both morphologically and epidemiologically) are not equivalent to cases with $\mathrm{ADH}$ that coexists with invasive ductal carcinoma. We did not see any amplification in $\mathrm{DH}$, which is consistent with results of several previous studies $(11,12)$ and in contrast those in to other reports $(15,29)$. In those latter reports, Her-2/neu overexpression was moderate or mild and was detected by the IHC method. The relative nonfidelity of IHC and the general problems related to quantitative IHC are two major obstacles in interpreting those results. We did not observe any amplification of Her-2/neu in normal ducts or lobules. However, a group of investigators has demonstrated that the normal-appearing epithelium adjacent to invasive breast cancers showed a low degree of Her-2/neu amplification (10). Those normal-appearing epithelial cells may be genetically similar to ADH or may be an admixture of normal and pagetoid infiltrating single cancer cells that cannot be recognized morphologically. We further observed that one Her-2/ neu-amplified invasive carcinoma was accompanied by a low-grade, nonamplified cribriform type of DCIS. This may either suggest that the two lesions developed independently or that a small population of cells within the DCIS with Her-2/neu amplification that was below the threshold of our assay or was unsampled selectively progressed into the invasive stage. These data add evidence supporting the hypothesis of multiple pathways to explain breast oncogenesis (14).

Close concordance between the amplification or overexpression of Her-2/neu in primary and metastatic breast carcinoma has been documented in a few reports (30-32) and was also observed in this study. This is in contrast to the heterogeneity of DNA ploidy in primary and metastatic carcinomas (32). Our series included several patients with Her2/neu-amplified invasive carcinomas who had either multiple positive axillary lymph nodes or multiple foci of metastatic tumor with different morphology in a single node. These morphologically heterogeneous tumor populations also showed heterogeneity of DNA ploidy as detected by FISH. Yet, despite morphological and numerical chromosomal heterogeneity, all cases with amplification of Her-2/neu had similar amplification ratios in both primary and multiple metastatic carcinomas. The mechanism by which Her-2/neu is selectively expressed or amplified in those heterogeneous tumors is unclear, but it may be due to survival advantage of those metastatic tumor cells with amplification or overexpression of Her-2/ neu $(18,33,34)$. In vitro and animal studies have shown that Her-2/neu protein is involved in control of the motility of tumor cells, migration through the extracellular matrix, and secretion of enzymes that degrade basement membrane $(18,33)$. This may explain why Her-2/neu amplification is associated with a higher metastatic potential in breast carcinomas mediated either by lymphatic or hematogeneous pathways $(33,35,36)$. As compared with tumors without amplification or overexpression of Her-2/neu, there are increased numbers of involved lymph nodes in the overexpressing cases (37). Those data indicate that the amplification or overexpression of Her-2/neu is quite stable through metastasis once it is established. This information may be important for management decisions in recurrent or metastatic cancers in determining whether anti-Her-2/neu therapy is applicable or necessary.

\section{REFERENCES}

1. Brandt-Rauf PW, Pincus MR, Carney WP. The c-erb B-2 protein in oncogenesis: molecular structure to molecular epidemiology. Crit Rev Oncog 1994;5:313-29.

2. Ross JS, Fletcher JA. HER-2/neu (c-erb-B2) gene and protein in breast cancer. Am J Clin Pathol 1999;112:S53-67.

3. Mitchell MS, Press MF. The role of immunohistochemistry and fluorescence in situ hybridization for HER2/neu in assessing the prognosis of breast cancer. Semin Oncol 1999; 26:108-16.

4. Harbeck N, Ross JS, Yurdseven S, Dettmar P, Polcher M, Kuhn W, et al. HER-2/neu gene amplification by fluorescence in situ hybridization allows risk-group assessment in node-negative breast cancer. Int J Oncol 1999;14:663-71.

5. Press MF, Bernstein L, Thomas PA, Meisner LF, Zhou JY, Ma $\mathrm{Y}$, et al. HER-2/neu gene amplification characterized by fluorescence in situ hybridization: poor prognosis in nodenegative breast carcinomas. J Clin Oncol 1997;15:2894-904.

6. Xing WR, Gilchrist KW, Harris CP, Samson W, Meisner LF. FISH detection of HER-2/neu oncogene amplification in early onset breast cancer. Breast Cancer Res Treat 1996;39: 203-12.

7. Marsigliante S, Muscella A, Ciardo V, Barker S, Leo G, Baker $\mathrm{V}$, et al. Enzyme-linked immunosorbent assay of HER-2/neu gene product (p185) in breast cancer: its correlation with sex steroid receptors, cathepsin D and histologic grades. Cancer Lett 1993;75:195-206.

8. Farabegoli F, Ceccarelli C, Santini D, Baldini N, Taffurelli M, Marrano D, et al. c-erbB-2 over-expression in amplified and non-amplified breast carcinoma samples. Int J Cancer 1999; 84:273-7.

9. Makar AP, Desmedt EJ, De Potter CR, Vanderheyden JS, Schatteman EA. Neu (C-erbB-2) oncogene in breast cancer 
and its possible association with the risk of distant metastases. A retrospective study and review of literature. Acta Oncol 1990;29:931-4.

10. Ratcliffe N, Wells W, Wheeler K, Memoli V. The combination of in situ hybridization and immunohistochemical analysis: an evaluation of Her2/neu expression in paraffin-embedded breast carcinomas and adjacent normal-appearing breast epithelium. Mod Pathol 1997;10:1247-52.

11. Mommers EC, van Diest PJ, Leonhart AM, Meijer CJ, Baak JP. Expression of proliferation and apoptosis-related proteins in usual ductal hyperplasia of the breast. Hum Pathol 1998;29: $1539-45$.

12. Stark A, Hulka BS, Joens S, Novotny D, Thor AD, Wold LE, et al. HER-2/neu amplification in benign breast disease and the risk of subsequent breast cancer. J Clin Oncol 2000;18: 267-74.

13. Kalogeraki A, Tzardi M, Datseris G, Kanavaros P, Karvelas C, Chalkiadakis G, et al. C-erbB-2: expression in patients with breast carcinoma in comparison to patients with benign breast diseases. Anticancer Res 1996;16:765-71.

14. Tsuda H, Hirohashi S. Multiple developmental pathways of highly aggressive breast cancers disclosed by comparison of histological grades and c-erbB-2 expression patterns in both the non-invasive and invasive portions. Pathol Int 1998;48: $518-25$.

15. Allred DC, Clark GM, Molina R, Tandon AK, Schnitt SJ, Gilchrist KW, et al. Overexpression of HER-2/neu and its relationship with other prognostic factors change during the progression of in situ to invasive breast cancer. Hum Pathol 1992;23:974-9.

16. Schmitt FC, Figueredo P, Lacerda M. Expression of c-erb B-2 prptein and DNA ploidy in breast carcinogenesis. Arch Pathol Lab Med 1995;119:815-20.

17. Slamon DJ, Clark GM. Amplification of C-ERB-B2 and aggressive breast tumors? Science 1988;240:1795-8.

18. Hung M-C, Lau Y-K. Basic sciences of Her-2/neu: a review. Semin Oncol 1999;26:51-9.

19. DiGiovanna MP, Lerman MA, Coffey RJ, Muller WJ, Cardiff $\mathrm{RD}$, Stern DF. Active signaling by Neu in transgenic mice. Oncogene 1998;17:1877-84.

20. Rohan TE, Hartwick W, Miller AB, Kandel RA. Immunohistochemical detection of c-erbB-2 and p53 in benign breast disease and breast cancer risk. J Natl Cancer Inst 1998;90: 1262-9.

21. Press MF, Hung G, Godolphin W, Slamon DJ. Sensitivity of HER-2/neu antibodies in archival tissue samples: potential source of error in immunohistochemical studies of oncogene expression. Cancer Res 1994;54:2771-7.

22. Masood S, Bui MM, Yung JF, Mark HF, Wong EY, Birkmeier $\mathrm{JM}$, et al. Reproducibility of LSI HER-2/neu SpectrumOrange and CEP 17 SpectrumGreen Dual Color deoxyribonucleic acid probe kit. For enumeration of gene amplification in paraffin-embedded specimens: a multicenter clinical validation study. Ann Clin Lab Sci 1998;28:215-23.

23. van Diest PJ, van Dam P, Henzen-Logmans SC, Berns E, van der Burg ME. A scoring system for immunohistochemical staining: consensus report of the Task Force for Basic Research the EORTC-GCGC. J Clin Pathol 1997;50:801-4.

24. Persons DL, Borelli KA, Hsu PH. Quantitation of HER-2/neu and c-myc gene amplification in breast carcinoma using fluorescence in situ hybridization. Mod Pathol 1997;10:720-7.

25. Meissner K, Riviere A, Haupt G, Loning T. Study of neuprotein expression in mammary disease. Am J Pathol 1990; 137:1305-9.

26. Vysis Inc. Path Vysion ${ }^{\mathrm{TM}}$ HER-2 DNA probe [package insert]. 1999.
27. Illei P, Feiner H, Symmans WF, Mitnick JS, Roses DF, Perle MA. Numerical abnormalities of chromosomes 7, 18, and X in precancerous breast disease defined by fluorescent in situ hybridization. Breast J 1998;4:252-7.

28. Tomaszewska R, Okon K, Nowak K, Stachura J. HER-2/Neu expression as a progression marker in pancreatic intraepithelial neoplasia. Pol J Pathol 1998;49:83-92.

29. De Potter CR, Van Daele S, Van de Vijver MJ, Pauwels C, Maertens G, De Boever J, et al. The expression of the neu oncogene product in breast lesions and in normal fetal and adult human tissues. Histopathology 1989;15:351-62.

30. Niehans GA, Singleton TP, Dykoski D, Kiang DT. Stability of HER-2/neu expression over time and at multiple metastatic sites. J Natl Cancer Inst 1993;85:1230-5.

31. Tommasi S, Giannella C, Paradiso A, Barletta A, Mangia A, Simone G, et al. HER-2/neu gene in primary and local metastatic axillary lymph nodes in human breast tumors. Int J Biol Markers 1992;7:107-13.

32. Symmans WF, Liu J, Knowles DM, Inghirami G. Breast cancer heterogeneity: evaluation of clonality in primary and metastatic lesions. Hum Pathol 1995;26:210-6.

33. Roetger A, Merschjann A, Dittmar T, Jackisch C, Barnekow A, Brandt B. Selection of potentially metastatic subpopulations expressing c-erbB-2 from breast cancer tissue by use of an extravasation model. Am J Pathol 1998;153:1797-806.

34. De Potter CR, Schelfhout AM. The neu-protein and breast cancer. Virchows Arch 1995;426:107-15.

35. Tiwari RK, Borgen PI, Wong GY, Cordon-Cardo C, Osborne MP. HER-2/neu amplification and overexpression in primary human breast cancer is associated with early metastasis. Anticancer Res 1992;12:419-25.

36. De Potter CR, Beghin C, Makar AP, Vandekerckhove D, Roels $\mathrm{HJ}$. The neu-oncogene protein as a predictive factor for haematogenous metastases in breast cancer patients. Int $\mathrm{J}$ Cancer 1990;45:55-8.

37. Mittra I, Redkar AA, Badwe RA. Prognosis of breast cancer: evidence for interaction between c-erbB-2 overexpression and number of involved axillary lymph nodes. J Surg Oncol 1995;60:106-11.

38. Pauletti G, Godolphin W, Press MF, Slamon DJ. Detection and quantitation of HER-2/neu gene amplification in human breast cancer archival material using fluorescence in situ hybridization. Oncogene 1996;13:63-72.

39. Jimenez RE, Wallis T, Tabasczka P, Visscher DW. Determination of Her-2/neu status in breast carcinoma: comparative analysis of immunohistochemistry and fluorescent in situ hybridization. Mod Pathol 2000;13:37-45.

40. Ross JS, Fletcher JA. The HER-2/neu oncogene: prognostic factor, predictive factor and target for therapy. Semin Cancer Biol 1999;9:125-38.

41. Cuny M, Simony-Lafontaine J, Rouanet P, Grenier J, Valles H, Lavaill R, et al. Quantification of ERBB2 protein expression in breast cancer: three levels of expression defined by their clinico-pathological correlations. Oncol Res 1994;6:16976 .

42. Ross JS, Fletcher JA. The HER-2/neu oncogene in breast cancer: prognostic factor, predictive factor, and target for therapy. Stem Cells 1998;16:413-28.

43. Schaller G, Bangemann N, Becker C, Buhler H, Opri F, Weitzel HK. Therapy of metastatic breast cancer with humanized antibodies against the HER2 receptor protein. J Cancer Res Clin Oncol 1999;125:520-4.

44. Goldenberg MM. Trastuzumab, a recombinant DNA-derived humanized monoclonal antibody, a novel agent for the treatment of metastatic breast cancer. Clin Ther 1999;21: 309-18. 